\title{
Analysis of the impact of electric vehicles on the power grid
}

\author{
Leszek Kasprzyk ${ }^{1, *}$, Robert Pietracho ${ }^{1}$, and Karol Bednarek ${ }^{1}$ \\ ${ }^{1}$ Poznan University of Technology, Institute of Electrical Engineering and Electronics, \\ ul. Piotrowo 3A, 60-965 Poznań, Poland
}

\begin{abstract}
The paper presents problems related to the impact of electric vehicles connected to the power grid on energy parameters. Basic methods of control in power grids were discussed and results of the simulation were presented with regards to the power distribution, voltage drops and losses in the transmission lines. The simulation was conducted based on the example of CIGRE 11, to which electric vehicle charging stations were connected in several selected points, with the possibility of energy release into the grid. The obtained results were compared for the simulation conducted in two variants - without the connected electric vehicles and with them. The obtained results were analyzed and commented upon.
\end{abstract}

\section{Introduction}

The function of the power grid is the continuous and stable transmission of electricity from the point of its generation to the final recipients [1]. This aim entails the necessity of control and optimal $[2,3,4,5,6]$ steering of the amount of the generated energy, as well as of its supply to the recipients in accordance with the current demand and with appropriate quality [7]. For energy companies, this is a task which is difficult to perform, taking into account the periods during which fluctuations of balance between the energy demand and supply may occur. These periods could refer to situations when the demand exceeds the productive capacity of units or when the excessive generation coming from renewable energy sources takes place $[8,9,10,11,12]$. The precise control of the technical condition of the power grid and the appropriate monitoring systems for electricity parameters (voltage, current and frequency) are necessary for the proper functioning of the system, avoiding the emergency conditions, i.e. failures $[2,13]$. Prevention of failures constitutes the priority for the power grid. Based on the data from the National Power System and the Balancing Market, it is possible to observe an increase in electricity consumption over the last decade $[14,15]$. In connection with the growing population ratio in Europe, the said increase may be observed in the case of other EU member states, which has been presented in the article [6]. In order to meet the requirements regarding the stable functioning of the system, the so called Smart Grid is implemented more and more often $[15,17]$. The said grid allows for the monitoring of the grid parameters in real time. Furthermore, it allows for the exchange of information

${ }^{*}$ Corresponding author: leszek.kasprzyk@put.poznan.pl 
between the system operators at any voltage level. The exchange is possible owing to the standardized protocol, whose proposal for implementation was presented in the paper [18].

The interoperation of smart grids with the power grid allows for the activation of the gathered data and the implementation of decision algorithms, whose task is the speedy and correct reaction in the case of disturbances in the grid lines [19]. In reference to the smart grids, it must be taken into account that this is an element whose task is to process the collected data. The change in the generation is related to the use of additional sources and energy storages such as: pumped-storage power plants [20], compressed air energy storages [21], fuel cells [22], battery packs [23, 24], flywheel energy storages [25] or supercapacitors [26]. The division of the said storages is described in papers [15, 27, 28]. They fulfill an intervention function, responding to a change in the load in the system nodes within the time ranging between several dozens of seconds and several minutes. The use of these sources is often related to geographical conditions in the given region, therefore their use is limited [29]. For this reason, battery packs whose powers reach $100 \mathrm{MW}$ are used more and more often, which makes them an excellent buffer for the dynamic changes in the demand occurring in the grid. The battery packs are also used in electric vehicles asan alternative energy source in hybrid systems [15, 30, 31, 32], whose sale in the recent years has been growing rapidly [33]. Taking into account the growth of sale of these vehicles, it can be assumed that the installed power resulting from the capacity of the batteries of vehicles connected to the electrical grid will grow. Taking into account the number of cars connected to the grid, this creates the possibility of using the accumulated energy by the operators of the system to control the parameters of the power grid. This is possible in the case of using the Smart Grid, twodirectional charging stations and appropriate control algorithms. Attention must be paid to the fact that electric vehicles are charged at the moment when the user does not use the vehicle. Most frequently these, are the evening and night hours, where it is possible to observe a decrease in the demand and reduction in generation by producers. Between 8:00 a.m. and 1.00 p.m., there is an increase in demand and the maximum values are achieved. In order to reduce the generation in these hours, the controlled discharge of the vehicles and the partial coverage of the demand are possible. The installed power in the vehicles may also serve the purpose of covering the local power losses. The work on the interoperation of electric vehicles with the power grid are presented in papers $[34,35]$.

\section{Methods of control in power grids}

The operation of the power system consists of the coverage of the energy demand and system losses. Because of this, there is a necessity of constant control of the active power balance and rotational speed of turbo-generators. The value of voltage and frequency in the grid may increase or decrease depending on such factors as: intermittent operation of recipients, activation/deactivation of loads with high powers, the change in the operating status of the turbine. As a result of this, the steam turbine blades may be subject to resonance, an increase in the iron losses, a change in the current in distribution system lines, etc. In order to maintain the correctness of parameters related to the quality of supplied energy, three methods of control are used: primary, secondary, tertiary. The primary control is the method of improvement of the electricity parameters by means of turbine speed controllers, whose response time is measured in seconds [36]. The secondary control consists in the control of power and frequency by the automatic exchange power and frequency control system. This control takes place by modifying the active power of turbo-generators within the time ranging between several seconds and 15 minutes. It is activated automatically and controls the operating parameters of the given energy block in such a way as to restore the proper electricity parameters in the system. The tertiary control refers to the rebuilding of the secondary control reserves [36]. Table 1 presents the technical requirements regarding the 
control services in the power grids, compliant with the Continental Europe Operation Handbook of ENTSO-E [36].

Table 1. Technical requirements for control services [36].

\begin{tabular}{|c|c|c|c|}
\hline \multirow{2}{*}{$\begin{array}{c}\text { Control } \\
\text { parameter }\end{array}$} & \multicolumn{3}{|c|}{ Control type } \\
\hline & primary control & secondary control & tertiary control \\
\hline Response time & $<30 \mathrm{~s}$ & $<5$ min & $<15$ min \\
\hline $\begin{array}{l}\text { Activation } \\
\text { method }\end{array}$ & automation system & automation systems & $\begin{array}{l}\text { automation systems or } \\
\text { voice communication }\end{array}$ \\
\hline Duration & continuous & 2 blocks, $12 \mathrm{~h}$ each & 6 block $4 \mathrm{~h}$ earch \\
\hline Minimum power & $1 \mathrm{MW}$ & $5 \mathrm{MW}$ & $5 \mathrm{MW}$ \\
\hline $\begin{array}{c}\text { Power control } \\
\text { direction }\end{array}$ & $\begin{array}{l}\text { growth and reduction } \\
\text { (one service) }\end{array}$ & $\begin{array}{l}\text { growth and reduction } \\
\text { (two separate services) }\end{array}$ & $\begin{array}{l}\text { growth and reduction } \\
\text { (two separate services) }\end{array}$ \\
\hline
\end{tabular}

At present, the most effective method to store energy for the purposes of the power system parameter control involves the use of pumped storage power plants. They are characterized by both the high energy capacity and the high dynamics of power reserve variations, therefore, their emergency presence improves the system's operating stability. For the Polish power system, storage of the energy in such power stations is a difficult and complex task because of their small number. Therefore, it is necessary to perform research regarding the possibility of using other types of energy storages, which could affect the correct operation of the system positively and protect the recipients from electricity supply failures. Because of the increasing popularity of electric vehicles and the development of the energy storages used by them (the growing capacity and effectiveness), the next chapter is devoted to analysis of the power distribution in the exemplary power grid to which electric vehicles with the possibility of transferring energy to the grid were connected.

\section{Calculation example}

In order to carry out analysis of the impact of charging several groups of electric vehicles and the potential options for the control of electricity parameters in power grids, an application in the Matlab environment was prepared to determine the power and energy losses in the grid. The simulation also took into account voltage amplitude variations in the nodes under consideration. The simulation tests were conducted for the CIGRE 11 grid model with the topology presented in Figure 1. The transmission lines were modeled as a four-terminal network, type $\Pi$, with parameters listed in Table 1 . The values of power generated in the respective grid nodes are presented in Table 2. An assumption was made that the electric vehicle charging stations were connected to the following nodes: N5, N6 and N9. Another assumption was that these vehicles (charging stations) could transfer the energy to the grid in a controlled manner. Their charge/discharge profiles are presented in the graphic form in Figure 2. The profiles present the aggregate power of the charging stations, which cover the group of several dozens of vehicles: in the EV1 700 station - vehicles with the $2.2 \mathrm{MW}$ power, in the EV2 500 station - vehicles with the 1.6 MW power and in the EV3 1000 station - vehicles with the $3.2 \mathrm{MW}$ power. For such a configuration of the grid, the following analyses were conducted:

- analysis of power distribution, voltage values as well as power losses and daily energy losses without considering electric vehicles,

- analysis of power distribution, voltage values as well as power losses and daily energy losses for the same configuration taking into account a group of electric vehicles. 


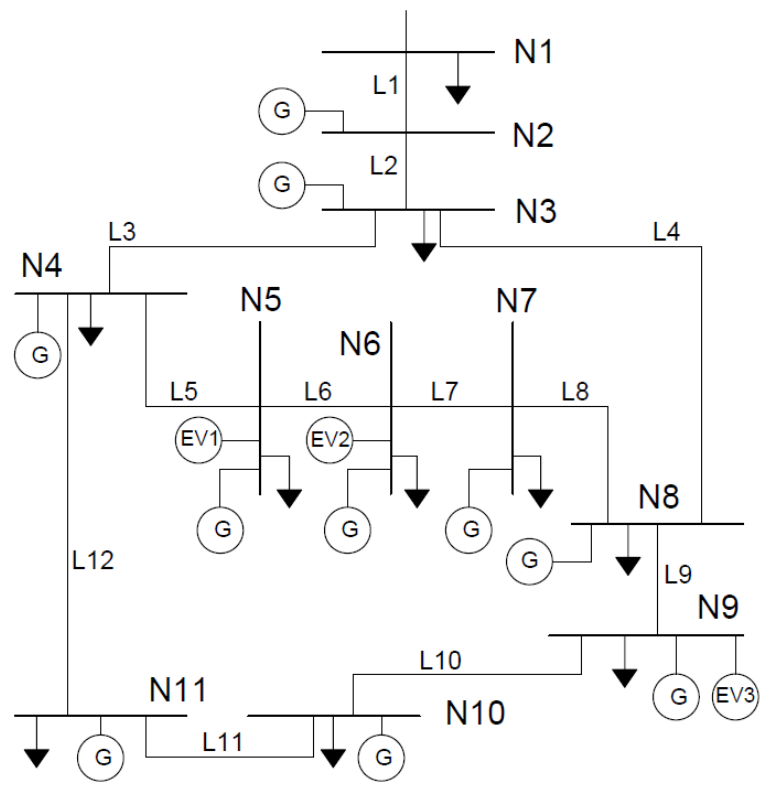

Fig. 1. Model of the medium voltage grid $20 \mathrm{kV}$ - CIGRE 11 [37].

Table 1. Specification of transmission line parameters [37].

\begin{tabular}{|c|c|c|c|c|c|}
\hline $\begin{array}{c}\text { Line } \\
\text { no. }\end{array}$ & $\begin{array}{c}\text { From } \\
\text { node }\end{array}$ & $\begin{array}{c}\text { To } \\
\text { node }\end{array}$ & $\mathbf{R}[\mathbf{\Omega}]$ & $\mathbf{X}[\mathbf{\Omega}]$ & $\mathbf{B}[\boldsymbol{\mu S}]$ \\
\hline L1 & N1 & N2 & 0.4082 & 0.2587 & 0.056005 \\
\hline L2 & N2 & N3 & 0.1812 & 0.1249 & 3.65090 \\
\hline L3 & N3 & N4 & 0.0400 & 0.0185 & 0.49410 \\
\hline L4 & N3 & N8 & 0.0559 & 0.0374 & 1.06860 \\
\hline L5 & N4 & N5 & 0.0496 & 0.0181 & 0.31920 \\
\hline L6 & N5 & N6 & 0.1409 & 0.0485 & 1.05640 \\
\hline L7 & N6 & N7 & 0.0154 & 0.0078 & 0.13680 \\
\hline L8 & N7 & N8 & 0.1227 & 0.0514 & 1.16900 \\
\hline L9 & N8 & N9 & 0.0271 & 0.0104 & 0.17472 \\
\hline L10 & N9 & N10 & 0.0768 & 0.0256 & 0.46508 \\
\hline L11 & N10 & N11 & 0.0303 & 0.0110 & 0.18810 \\
\hline L12 & N11 & N4 & 0.0518 & 0.0164 & 0.27930 \\
\hline
\end{tabular}

Table 2. Generation node parameters.

\begin{tabular}{|c|c|c|c|c|c|c|c|c|c|c|c|}
\hline Node & N1 & N2 & N3 & N4 & N5 & N6 & N7 & N8 & N9 & N10 & N11 \\
\hline P [MW] & 0.0 & 3.9 & 0.7 & 1.25 & 2.35 & 0.8 & 1.0 & 2.3 & 1.0 & 1.6 & 1.5 \\
\hline
\end{tabular}

During the conducted tests, power distribution in the grid under consideration and voltage values in the respective nodes were analyzed. Figure 3 presents differences in the power demand variations in selected grid nodes (N5, N6 and N9), which were considered the most important from the point of view of impact of electric vehicles on the power grid (they were characterized by significant variations). On their basis, it is possible to notice that the load curve was aligned, which positively affected the performance of generating units. While analyzing the obtained results, it is worth paying particular attention to the impact of the process of the charge and controlled discharge of electric vehicles on daily power losses, which was presented in Figure 4, and the daily energy losses in transmission lines, which 
were presented in Figure 5. Furthermore, the voltage amplitude values were compared for nodes N2 and N6 (Fig. 6).
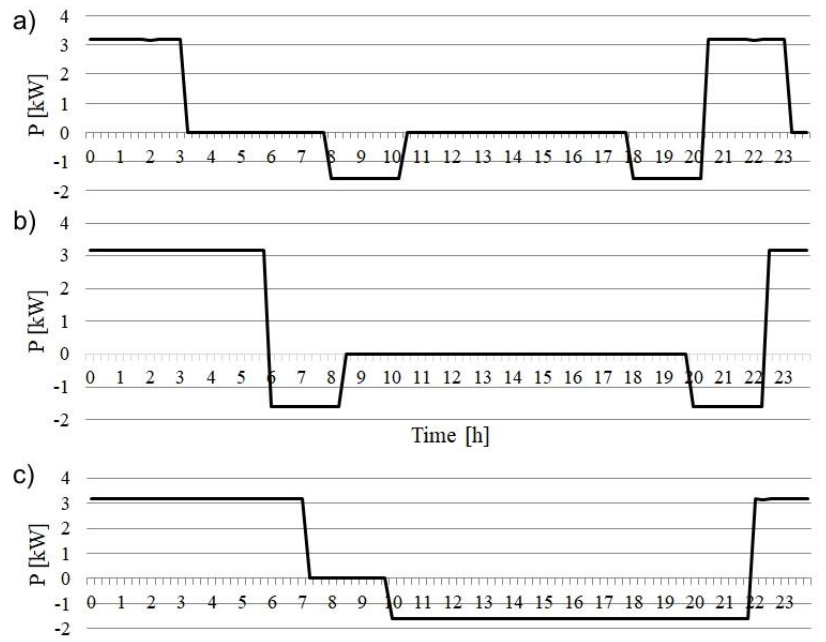

Fig. 2. Assumed profiles of electric vehicle charging stations: a) EV1, b) EV2, c) EV3.

These nodes were selected as they were characterized by the smallest and greatest voltage amplitude changes (voltage waveforms in the remaining nodes are between these waveforms). It follows from them that during the periods in which electric vehicles are switched on, voltage in the grid changes by several percent, which proves that they can constitute emergency energy sources which support the solutions for the problem of control in the power grids.

a)

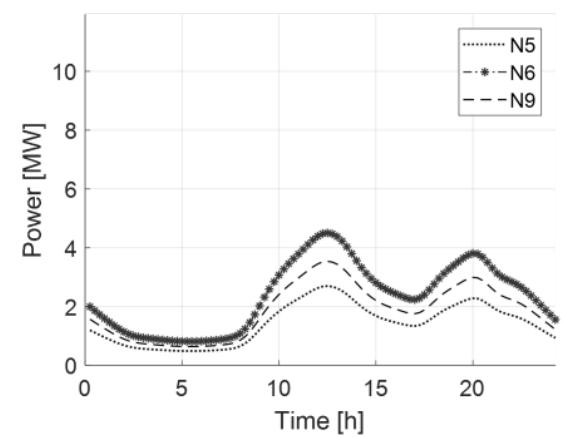

b)

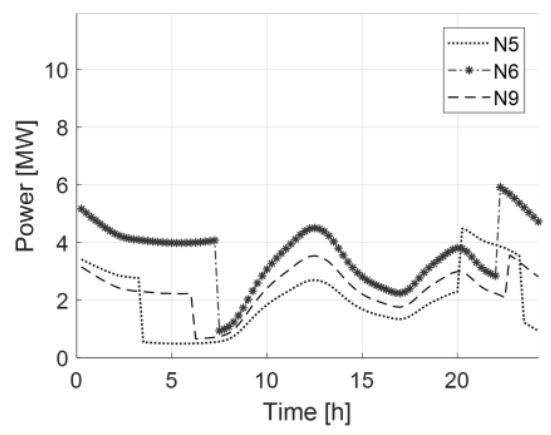

Fig. 3. Grid load characteristics in the selected nodes: a) without EV, b) with EV. 


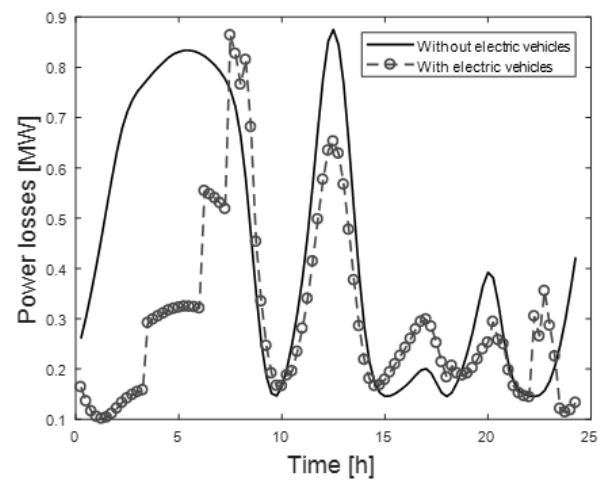

Fig. 4. Comparison of total power losses in the lines of the power grid under consideration, without and with electric vehicles.

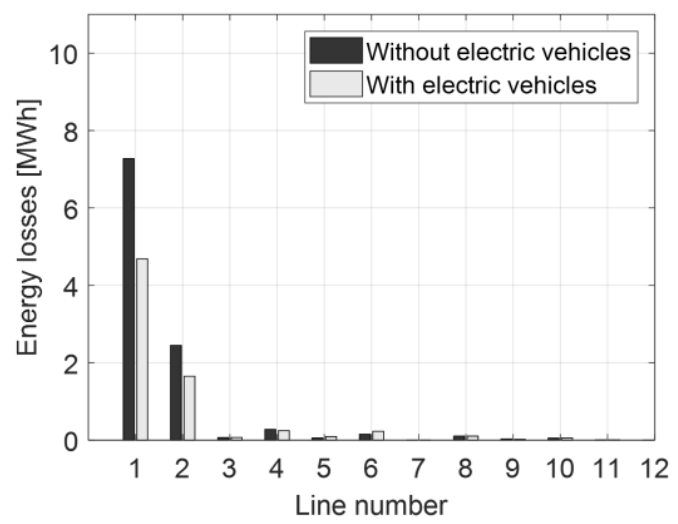

Fig. 5. Daily energy losses in the grid under consideration.

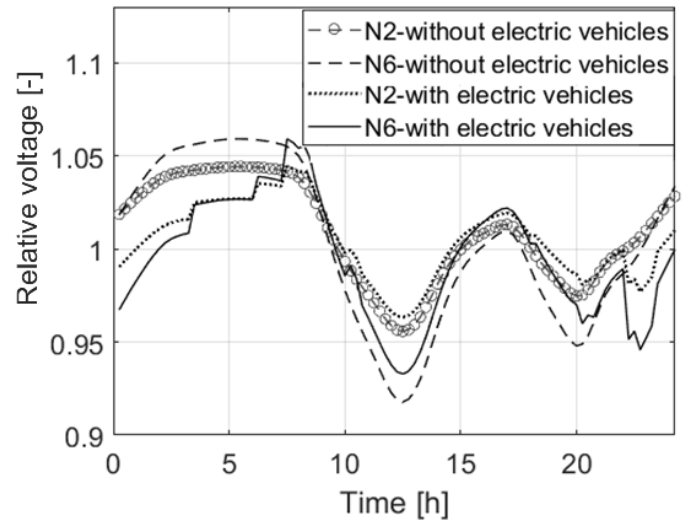

Fig. 6. Relative voltage amplitude in nodes N2 and N6.

\section{CONCLUSIONS}

The results obtained during the conducted simulation confirm the possibility of using batteries of electric vehicles to improve the energy parameters in power grids. The vehicles 
affect the shape of the daily load curve and the voltage amplitude values. They can also constitute an energy source which is able to respond to local power losses in the system, improving the voltage values and eliminating the energy losses during the day. Such a solution, however, requires the appropriate communication between structures in the system and the determination of rules of interoperation of the vehicles with the power system (reduction in the depth of discharge of energy storages in vehicles or the financial settlement with the vehicle owner).

With the planned use of the electric vehicle batteries for the support of the power system, an important aspect is the strict control and planned exploitation of these sources. At present, the basic issue regarding the use of the energy accumulated in the storages used in electric vehicles is the battery per se. Its life is strictly determined by the intensity of aging processes, therefore, an economic analysis, which will allow for the determination of benefits, resulting from e-mobility is required.

During further research on the possibility of using electric vehicles, the development of the algorithm which will allow for a more effective use of the potential of electrochemical energy storages is planned to improve the parameters in the power grids (grid parameter control). An increase in the control efficiency is possible through the optimization of control of the process of charge or possible emergency discharge into the power grid in such a way as to minimize the difference between the extreme values of daily power demand (especially a decrease in the demand during peak hours).

\section{References}

1. T. Khal, Sieci elektroenergetyczne, Wydawnictwo Naukowo-Techniczne, (1984)

2. J. Jajczyk, A. Dobrzycki, M. Filipiak, D. Kurz, E3S Web of Conferences, 19, 01027 (2017)

3. K. Bednarek, R. Nawrowski, A. Tomczewski, Prz. Elektrotechniczny, 84/1, 62-64 (2008)

4. R. Nawrowski, A. Tomczewski, K. Bednarek, International Conference on Parallel Computing in Electrical Engineering, (PARELEC, 218-222, 2000)

5. K. Bednarek, , Prz. Elektrotechniczny, 84/12, 138-141 (2008)

6. L. Kasprzyk, Prz. Elektrotechniczny, 88/7B, 131-133 (2012)

7. K. Bednarek, L. Kasprzyk, Prz. Elektrotechniczny, 88/12b, 236-239 (2012)

8. A. M. Eltawil, Z. Zhengming, Renew. Sust. Energ. Rev., 14/1, 112-129 (2010)

9. A. Tomczewski, Sci. World J., 643769 (2014)

10. D. Głuchy, D. Kurz, G. Trzmiel, Prz. Elektrotechniczny, 89/6, 78-80 (2013)

11. K. Skowronek, G. Trzmiel, Prz. Elektrotechniczny, 83/11, 108-110 (2007)

12. G. Trzmiel, Eksploat. Niezawodn., 19, 516-521 (2017)

13. G. Andersson, P. Donalek, R. Farmer, N. Hatziargyriou, I. Kamwa, P. Kundur, N. Martins, J. Paserba, P. Pourbeik, J. Sanchez-Gasca, R. Schulz, A. Stankovic, C. Taylor, V. Vittal, IEEE Trans. Power Syst., 20/4, (2005)

14. https://www.pse.pl/

15. L. Kasprzyk, Eksploat. Niezawodn., 19, 229-236 (2017)

16. J. Torriti, G. M. Hassan, M. Leach, Energy, 35/4, 1575-1583 (2010)

17. R. J. Roncero, SmartGrids for Distribution, (CIRED Seminar, 1-4, 2008) 
18. A. Naumann, I. Bielchev, N. Voropai, Z. Styczynski, Control Eng. Practice, 25, 102-111 (2014)

19. L. Kasprzyk, A. Tomczewski, K. Bednarek, Prz. Elektrotechniczny, 87/12b, 82-85 (2011)

20. A. K. Varkani, A. Daraeepour, H. Monsef, Appl. Energy, 88/12, 5002-5012 (2011)

21. H. Lund, G. Salgi, Energy Conv. Manag., 50/5, 1172-1179 (2009)

22. B. Bolund, H. Bernhoff, M. Leijon, Renew. Sust. Energ. Rev., 11/2, 235-258 (2007)

23. M. G. Cook, C. W. Spindler, G. Grefe, IEEE Trans. Energy Convers., 6/1 (1991)

24. D. Burzyński, L. Kasprzyk, E3S Web of Conferences, 14, 01041 (2017)

25. B. Bolund, H. Bernhoff, M. Leijon, Renew. Sust. Energ. Rev., 11/2, 235-258 (2007)

26. D. Głuchy, L. Kasprzyk, Prz. Elektrotechniczny, 93/12, 99-102 (2017)

27. L. Kasprzyk, K. Bednarek, Acad. Journ., Elec. Eng., 69, 199-218 (2012)

28. H. Chen, N. T. Cong, W. Yang, C. Tan, Y. Li, Y. Ding, Progr. in Nat. Scien., 19/3, 291312 (2009)

29. D. Kurz, International Conference Computational Problems of Electrical Engineering, (ICCPEE, 1-5, 2016)

30. H. Liang, J. B. Choi, W. Zhuang, X. Shen, IEEE International Conference on Computer Communications, (INFOCOM,1674-1682, 2012)

31. K. B. Sovacool, F. R. Hirsh, Energy Policy, 37/3, 1095-1103 (2009)

32. L. Kasprzyk, K. Bednarek, Prz. Elektrotechniczny, 91/12, 129-132 (2015)

33. M. Jóźwicka, F. Hacker, F. Hulsmann, S. Kuhnel, L. Minnich, J. Purwanto, M. Bolech, European Environment Agency, (2016)

34. K. Mets, T. Verschueren, F. Truck, C. Develder, IEEE Smart Grid Modeling and Simulation, (SGMS, 7-12, 2011)

35. J. J. Escudero-Garzas, A. Garcia-Armanda, G. Seco-Granados, IEEE Transactions on Vehicular Technology, 61/8, (2012)

36. J. Wasilewski, K. Karkoszka, Polit. Energet., 19, 35-52 (2016)

37. https://e-cigre.org/ 